\title{
A VUELTAS CON LA PROBLEMÁTICA DEL INCIDENTE “EXCEPCIONAL" DE NULIDAD DE ACTUACIONES Y SU RELACIÓN CON EL RECURSO DE AMPARO CONSTITUCIONAL
}

\author{
BACK WITH THE PROBLEM OF THE "EXCEPTIONAL" \\ APPEAL FOR ANNULMENT AND ITS RELATION WITH \\ THE APPEAL FOR PROTECTION OF FUNDAMENTAL \\ RIGHTS
}

\author{
Ana LÓPEZ NAVÍO ${ }^{1}$
}

Recibido: 29/05/2020

Aceptado: 14/07/2020

SUMARIO: I. Consideraciones generales. II. El incidente “excepcional” de nulidad de actuaciones. 1. Naturaleza del incidente "excepcional” de nulidad de actuaciones según el tribunal constitucional. 2. Regulación del incidente "excepcional” de nulidad de actuaciones. III. Problemas que plantea el incidente "excepcional” de nulidad de actuaciones. 1. El incidente "excepcional” de nulidad de actuaciones como instrumento procesal para remediar lesiones de derechos fundamentales. 2. El carácter no devolutivo. 3. Derechos invocables. IV. La relación entre el incidente "excepcional” de nulidad de actuaciones y el recurso de amparo constitucional. 1. El incidente "excepcional” de nulidad de actuaciones como medio de acceso al recurso de amparo. 2. Problemática entre el incidente "excepcional de nulidad de actuaciones y el recurso de amparo constitucional. A. La imposibilidad de simultanear el incidente de nulidad de actuaciones y el recurso de amparo: los amparos prematuros. B. La preceptiva interposición del incidente “extraordinario" de nulidad de actuaciones previa al recurso de amparo. 3. El incidente "excepcional” de nulidad de actuaciones. ¿un efectivo filtro para el acceso al recurso de amparo constitucional? 4. El incidente "excepcional" de nulidad de actuaciones y la especial trascendencia constitucional. V. Conclusiones. VI. Bibliografía.

Resumen: El incidente “excepcional” de nulidad de actuaciones regulado en el art. 241 LOPJ es una figura que siempre ha ocasionado diversas controversias acerca de su correcta aplicación y de su funcionalidad. Esta problemática se vio acentuada con la reforma operada por la LO 6/2007 ocasionando así una gran inseguridad jurídica. A día de hoy, casi treces años después de esta reforma, siguen quedando diversas cuestiones por resolver. Es el objeto de este trabajo arrojar luz sobre las cuestiones que suscita esta figura, así como el estudio de una efectiva estrategia procesal para su correcta interposición y la posible presentación posterior de un recurso de amparo constitucional.

Palabras claves: Derechos fundamentales, garantías procesales, incidente de nulidad de actuaciones, recurso de amparo constitucional.

SUMMARY: I. General considerations. II. The "exceptional” appeal of annulment. 1. The nature of the "exceptional" appeal of annulment according to the constitutional court. 2. Regulation of the “exceptional” appeal of annulment. III. Problems raised by the "exceptional” appeal of annulment. 1. The “exceptional” appeal of annulment as a procedural instrument to remedy fundamental rights injuries. 2. The non-return character. 3. Allegeable rights. IV. The relation between the "exceptional” appeal of

1 * Profesora sustituta interina y doctoranda del Programa de Doctorado en Derecho de la Universidad de Jaén. alnavio@ujaen.es Researcher ID: I-2969-2015. Código Orcid０000-0002-4678-1696 
annulment and the appeal for protection of fundamental rights. 1. The "exceptional" appeal of annulment as a way of access to the appeal for protection of fundamental rights. 2. Problems between the "exceptional" appeal of annulment and the appeal for protection of fundamental rights. A. The impossibility of bringing together the "exceptional" appeal of annulment and the appeal for protection of fundamental rights. B. The required prior lodging of the "exceptional” appeal of annulment to the appeal for protection of fundamental rights. 3. The "exceptional" appeal of annulment, an effective filter for access to the appeal for protection of fundamental rights? 4. The "exceptional" appeal of annulment and the special constitutional trascende. V. Conclusions. VI. Bibliography.

Abstract: The "exceptional” appeal of annulment, which is regulated in art. 241 OLJP, is a figure that has always caused various controversies regarding its correct application and functionality. This problem was accentuated due to the reform operated by OL 6/2007, thus causing a great legal uncertainty. Today, almost thirteen years after this reform, there are still various questions to be resolved. The purpose of this work is to shed light on the issues raised by this figure, as well as the study of an effective procedural strategy for its correct filing and the possible subsequent presentation of an appeal for protection of fundamental rights.

Key words: fundamental rights, procedural guarantees, appeal for annulment, appeal for protection of fundamental rights.

\section{CONSIDERACIONES GENERALES}

El incidente "excepcional” de nulidad de actuaciones (en adelante, IENA), regulado en el art. 241 LOPJ, ha generado siempre controversias doctrinales ${ }^{2}$. Tras la reforma de la que fue objeto en 2007 esta problemática se vio acentuada notablemente, llegándose incluso a plantear la posible inconstitucionalidad del art. $241 \mathrm{LOPJ}^{3}$.

\footnotetext{
${ }^{2}$ El incidente "excepcional" de nulidad de actuaciones fue incorporado a nuestro ordenamiento con la LEC 1881. Debido a su transformación jurisprudencial en un recurso extraordinario y al abuso y utilización con efectos dilatorios, se produjo su supresión en 1984, subsumiéndose entonces en el sistema de recursos ordinarios todas las posibles nulidades. Fue de nuevo incorporado en la nueva redacción del art. 240 de la LO 6/1985, de 1 de julio, del Poder Judicial. Posteriormente, fue de nuevo modificado mediante la LO 5/1997, como consecuencia de la doctrina sentada en la STC 185/1990, de 15 de noviembre. Esta sentencia manifestó la necesidad de que el poder legislativo regulara adecuadamente el incidente de nulidad introduciendo la posibilidad de que el propio Juez que hubiera dictado la sentencia definitiva o firme pudiera anularla en determinados casos muy excepcionales. Posteriormente, la LO 13/1999 introdujo algunos arreglos en el citado precepto con el fin de perfeccionar la regulación de dicho incidente. La LEC 1/2000, de 7 de enero, prácticamente incorporó la regulación de la LOPJ de 1985. Esta Ley tenía una vocación de “código procesal general”, es decir, pretendía convertirse en la norma general procesal por aplicación directa o subsidiaria en lo no regulado en otras leyes de procedimiento que afectan a órdenes jurisdiccionales distintos del civil. En concreto esta Ley fue la que lo denominó como «incidente excepcional de nulidad de actuaciones». Con ello, por una parte, se incluía el incidente de nulidad de actuaciones en una norma procesal, lo que resulta más adecuado a su naturaleza y, por otra parte, se mantenía la aplicación del incidente de nulidad de actuaciones en todos los órdenes jurisdiccionales, debido al carácter supletorio de la LEC (art. 4 LEC). Además, reguló otros aspectos del incidente hasta el momento faltos de concreción normativa.

${ }^{3}$ Cfr. CASTRO MARTÍN, J. L., MORENILLA ALLARD, P., "Sobre la inconstitucionalidad del artículo 241.1.LOPJ, en cuanto que atribuye la competencia para el conocimiento y resolución del incidente excepcional de nulidad de actuaciones al mismo Tribunal que dictó la resolución judicial firme cuya rescisión se postula”, Diario La Ley, núm. 7784, Sección Doctrina, 2012. MORENILLA Allard, P., "De
} 
Esta figura fue originariamente configurada como un remedio de única o última instancia frente a vulneraciones de derechos procesales en sede jurisdiccional, el incidente cumple en la actualidad una función constitucional que emana del derecho a la tutela judicial efectiva y se conecta, además, con la garantía de los derechos fundamentales prevista en el art. 53.2 CE.

Sin embargo, su regulación y la aplicación que de ella están haciendo tanto los tribunales como el Tribunal Constitucional han provocado un cierto nivel de inseguridad jurídica, de modo que, actualmente, su función está siendo muy cuestionada. A día de hoy, más de una década después de su reforma, es necesario seguir hablando del incidente con el objetivo de aclarar cuál es su naturaleza y su función actual y si merece o no ser conservado en nuestro ordenamiento jurídico.

Debemos prestar especial atención a la influencia que el IENA tiene en el plazo para interponer el recurso de amparo, debido a que el art. $44.1 \mathrm{a}$ ) LOTC exige que se hayan agotado todos los medios de impugnación previstos por las normas procesales para el caso concreto dentro de la vía judicial. Esto puede originar, como veremos, problemas y dudas para los operadores jurídicos. Por un lado, puede originar que la falta de interposición de éste determine la inadmisión del recurso de amparo por falta de agotamiento de la vía judicial previa y, por otro lado, que su improcedente interposición determine que el recurso de amparo sea extemporáneo y, consecuentemente, también se inadmita.

Pretendemos arrojar luz sobre esta problemática para así poder diseñar una efectiva estrategia de litigio que ayude a los operadores jurídicos a saber cuándo y cómo han de interponer este instrumento. Trataremos de resolver aquellas cuestiones procesales referidas a la correcta interposición del IENA y su instrumentalización para la restricción del acceso al TC por la vía del recurso de amparo con el objetivo de lograr así una efectiva estrategia procesal que logre evitar la inadmisión del incidente y, en su caso, del posterior amparo constitucional.

\section{EL INCIDENTE “EXCEPCIONAL” DE NULIDAD DE ACTUACIONES}

En primer lugar, debemos destacar la utilización del término excepcional por dos motivos principalmente: el primero es para distinguirlo del incidente común del art. 240.2 LOPJ; el segundo, para resaltar ese carácter “excepcional” que la propia LOPJ subraya.

Es importante resaltar el hecho de que consideramos que la terminología no es del todo clara en este punto. $Y$ es que hemos podido comprobar que las denominaciones de ambos incidentes son algo confusas. El incidente "común" de nulidad de actuaciones del art. 240.2 LOPJ no suele ser llamado generalmente "incidente” pese a serlo. Por el contrario, el IENA pocas veces es denominado como "excepcional" sino que suele ser llamado incidente de nulidad de actuaciones, sin más, induciendo al error con respecto al incidente del art. 240.2 LOPJ. En nuestra opinión, consideramos que debería tenerse en consideración este hecho y dejar claro, de cara tanto a los operadores jurídicos como a los estudiosos de la materia, la diferencia entre ambas figuras, siendo el primero un incidente de carácter “común” y el segundo un incidente de carácter “excepcional”.

nuevo sobre la inconstitucionalidad del incidente de nulidad de actuaciones”, Diario La Ley. Sección Doctrina, núm. 8089, 2013. 
Es por este motivo, entre otros, por el que hemos considerado necesario el análisis de la nulidad de actuaciones antes de centrarnos en la figura del incidente "excepcional". Asimismo, el estudio de ambas figuras permite apreciar coincidencias entre los principios que las rigen, las causas, etc., pues ambas tienen como objetivo evitar la vulneración de derechos o "defectos de forma en los actos procesales que impliquen ausencia de los requisitos indispensables para alcanzar su fin o determinen efectiva indefensión”. De igual modo, ambos incidentes permiten la protección de los derechos fundamentales en la vía ordinaria (en el estudio de las causas de nulidad de pleno derecho hemos podido ver que muchas de ellas iban dirigidas a la protección de derechos fundamentales), hecho que no debemos olvidar ya que el incidente "excepcional”, aunque sea un medio específico para la protección de derechos fundamentales, no deja de ser un instrumento extraordinario.

\section{Naturaleza del incidente “excepcional” de nulidad de actuaciones según el Tribunal Constitucional}

Tras la modificación de 2007, debemos acudir a lo establecido por nuestro TC en su jurisprudencia para determinar la naturaleza de esta figura. Nuestro Alto Tribunal se ha pronunciado en reiteradas ocasiones acerca del nuevo sentido que ha querido darle a esta institución. Entre otras sentencias, la 153/2012, de 16 de julio, afirmó que "el incidente de nulidad de actuaciones asume, tras la configuración del nuevo amparo constitucional, una función esencial de tutela y defensa de los derechos fundamentales que puede y debe ser controlada por este Tribunal cuando las hipotéticas lesiones autónomas que en él se produzcan tengan especial trascendencia constitucional”.

No podemos considerarlo pues como un mero trámite formal previo al amparo constitucional, sino que constituye-un verdadero instrumento procesal que, en la vía de la jurisdicción ordinaria, podrá remediar aquellas lesiones de derechos fundamentales que "no hayan podido denunciarse antes de recaer resolución que ponga fin al proceso y siempre que dicha resolución no sea susceptible de recurso ordinario ni extraordinario" (art. 241.1 LOPJ).

La LOPJ regula esta figura en los artículos 238 y siguientes, además de los artículos 225 y siguientes de la LEC. Se trata de un instrumento procesal que ha sufrido numerosas modificaciones desde la entrada en vigor de la LOPJ.

La propia Exposición de Motivos de la LO 6/2007 indica que la utilidad fundamental de la nulidad de actuaciones es permitir a los órganos judiciales que integran el poder judicial realizar una protección primaria y principal de los derechos fundamentales reconocidos en la Constitución. De esta forma, se persigue que la intervención del TC, mediante el recurso de amparo, tenga una naturaleza residual ${ }^{4}$.

Como ya indicó CARRASCO DURÁN ${ }^{5}$, el IENA, tras la reforma de 2007, cuenta con varias características comunes con el recurso de amparo, como son su ámbito material, la excepcionalidad y la subsidiariedad. La diferencia con el recurso de amparo se encontraría en la articulación entre la dimensión subjetiva y la dimensión objetiva inherentes a los procesos destinados a la tutela de los derechos fundamentales.

\footnotetext{
${ }^{4}$ Puede consultarse: RUÍZ RUÍZ, J. J., “La jurisdicción constitucional”, en S. GAMBINO, J. LOZANO MIRALLES, F. PUZZO y J. J. RUÍZ RUÍZ, El sistema constitucional español, Instituto Nacional de la Administración Pública, Madrid, 2019, págs. 313 y ss.

${ }^{5}$ CARRASCO DURÁN, M., "La tutela de los derechos fundamentales a través del incidente de nulidad de actuaciones”, Revista Española de Derecho Constitucional, núm. 95, 2012, págs. 74-75.
} 
El recurso de amparo, tras esta reforma, vio minorada su dimensión subjetiva, es decir, fue "objetivado". Sin embargo, coincidiendo con el punto de vista del autor, en el incidente predomina la faceta subjetiva. Hecho entendible teniendo en cuenta el objetivo que persiguió esta reforma. La función de esta figura consiste, pues, en proporcionar a la parte en un proceso que haya sufrido una lesión en alguno de los derechos fundamentales del artículo 53.2 CE una forma rápida y sencilla de obtener la reparación de su derecho o interés legítimo, mediante la nulidad de la actuación procesal determinante de dicha lesión, siempre que se cumplan los requisitos establecidos en la legislación.

Sin embargo, debemos destacar que una deficiente protección de los derechos denunciados por parte del órgano judicial ordinario dejará al recurrente sin ningún tipo de protección en aquellos casos en los que las vulneraciones en las que supuestamente incurriera la resolución impugnada, a través del incidente de nulidad de actuaciones, carezcan de trascendencia constitucional, hecho consecuente de la ya citada reforma,

\section{Regulación del incidente "excepcional” de nulidad de actuaciones}

La regulación ${ }^{6}$ del IENA (art. 241 LOPJ y 228 LEC) establece que, excepcionalmente, quienes sean parte legítima o hubieran debido serlo podrán pedir por escrito que se declare la nulidad de actuaciones fundada en cualquier vulneración de un derecho fundamental de los referidos en el artículo 53.2 de la Constitución, siempre que no haya podido denunciarse antes de recaer resolución que ponga fin al proceso y siempre que dicha resolución no sea susceptible de recurso ordinario ni extraordinario ${ }^{7}$.

La competencia para poder conocer de la nulidad de las actuaciones es del mismo órgano que dictó la resolución que ha adquirido firmeza.

Respecto a la legitimación para interponerlo, ésta corresponde a quien fue parte en el proceso del que resultó la resolución firme objeto del incidente, así como a

\footnotetext{
${ }^{6}$ Para más información sobre la evolución normativa de esta figura, puede consultarse:

BELLIDO PENADÉS, R., "El incidente de nulidad de actuaciones como medio de tutela de derechos fundamentales”, Revista General de Derecho Constitucional, núm. 25, 2017, págs. 5 y ss.

NOGUEIRA GUSTAVINO, M., "Contracciones y dilataciones en la reforma de la Ley Orgánica del Tribunal Constitucional: parto prematuro del incidente de nulidad de actuaciones e incongruencia omisiva”, Teoría y Derecho, núm.3, 2008, págs. 206-232.

7 Para una mayor información sobre la regulación del incidente tras la reforma puede consultarse: AGUILERA MORALES, M., "El incidente de nulidad de actuaciones ex artículo 241 LOPJ: una mala solución para un gran problema”, Revista General de Derecho Procesal, núm. 31, 2013. ÁLVAREZ SÁNCHEZ DE MOVELLÁN, P., El incidente de nulidad de actuaciones. Solución o problema frente a la resolución firme, Madrid, 2015. BACHMAIER WINTER, L., "La reforma de la LOTC y la ampliación del incidente de nulidad de actuaciones”, Revista General de Derecho Procesal, núm., 13, octubre 2007. BANACLOCHE PALAO, J., "La reforma del incidente de nulidad de actuaciones y el pretendido amparo judicial”, en C. Banacloche Palao, J. Banacloche Pérez-Roldán, B. Banacloche Palao (coords.), Justicia y Derecho tributario. Libro homenaje al profesor Julio Banacloche Pérez, Madrid, 2008. DOIG DÍAZ, Y., "Análisis del nuevo incidente de nulidad de actuaciones en la Ley Orgánica 6/2007 de reforma del art. 241 LOPJ”, Diario La Ley, núm. 6889, Sección Doctrina, 2008. DOIG DÍAZ, Y., "El renovado incidente de nulidad de actuaciones. A propósito de la modificación de la LOTC. Práctica de Tribunales”, Revista de Derecho Procesal Civil y Mercantil, núm.46,2008. FERNÁNDEZ CABALLERO, G., "El incidente excepcional de nulidad de actuaciones. Teoría e incidencia práctica en el proceso civil tras su modificación por la ley orgánica 6/2007”, Revista Internacional de Estudios de Derecho Procesal y Arbitraje, núm. 2, 2012. MEGINO FERNÁNDEZ, D., El incidente de nulidad de actuaciones, Lisboa, 2010. VALDÉS DAL-RÉ, F., "El incidente de nulidad de actuaciones: su controvertida reforma por la Ley 6/2007”, Derecho de las Relaciones Laborales, núm. 2, 2015.
} 
quien debiera haberlo sido. El Ministerio Fiscal no siempre va a tener legitimación para plantear el incidente, pero podrá actuar como promotor o intervenir cuando hubiera sido parte en el proceso en que recayó la resolución que da pie a la interposición del incidente, o cuando debiera haber sido parte y sin embargo no intervino.

Debemos destacar en este punto, que esta legitimación del Ministerio Fiscal ha sido objeto de numerosas críticas, ya que la amplia legitimación (objetiva) de la que goza el Ministerio Fiscal para el planteamiento del amparo constitucional lleva a cuestionar el limitado alcance de su legitimidad para la interposición del incidente (ATC 36/2011).

El plazo para su presentación será de 20 días desde la notificación de la resolución, o desde que se tuvo conocimiento de la causa de indefensión, con un máximo de cinco años como plazo de caducidad a los efectos de poder interponer el incidente, contados desde la notificación de la resolución. En este punto, se nos plantean ciertos problemas respecto a los plazos para la interposición del incidente y para la posible interposición del recurso de amparo.

Respecto al procedimiento, una vez presentado el escrito, debemos tener en cuenta dos aspectos:

En primer lugar, si se ha vulnerado un derecho fundamental, no será necesario presentar un documento anejo a las actuaciones, ya que puede constatarse en ellas.

En segundo lugar, si esa vulneración no quedase establecida con las actuaciones y, por tanto, fuese necesario llevar a cabo la prueba, se estará a lo previsto por el art. 226 de la LEC, por lo que se citará a las partes a una comparecencia que se hará igual que lo que se prevé para la vista del juicio verbal.

Respecto a la decisión sobre la nulidad, ésta se emitirá mediante un auto, según el cual, puede producirse la desestimación de la solicitud, en cuyo caso el proceso terminaría ahí, y se podrá imponer al solicitante, las costas y, en su caso, una multa por temeridad. En caso de que se estime la solicitud, se declarará vulnerado el derecho fundamental mediante una resolución, con reposición de las actuaciones correspondientes y, a partir de ahí, se podría seguir el procedimiento normal.

Contra la resolución que resuelva el incidente no cabrá recurso alguno.

Destacar, por último, que el escrito que solicita la nulidad de actuaciones no produce el efecto de suspender la ejecución de la sentencia o de la resolución, a no ser que así lo pida la parte o se acuerde por el juez.

\section{PROBLEMAS QUE PLANTEA EL INCIDENTE “EXCEPCIONAL” DE NULIDAD DE ACTUACIONES}

\section{El incidente "excepcional" de nulidad de actuaciones como instrumento procesal para remediar lesiones de derechos fundamentales}

El IENA pretende corregir una vulneración de uno o varios derechos fundamentales invalidando lo actuado y dejando sin efecto la sentencia en cuestión. Ello, siempre que no se haya podido denunciar antes de que recaiga una resolución que ponga fin al proceso y siempre que dicha resolución no sea ya susceptible de recurso de apelación ni de casación ${ }^{8}$.

\footnotetext{
${ }^{8}$ La STC 155/2009, de 25 de junio, interrelacionó el recurso de amparo con el incidente “excepcional” de nulidad de actuaciones, perfilando los respectivos papeles a distribuir entre la jurisdicción ordinaria y la constitucional. Se introdujo como elemento más novedoso el requisito sustantivo o de fondo de la
} 
En palabras del propio TC en su Sentencia 87/2012, del 29 de octubre, FJ 9:

«Tras la reforma operada en la regulación del citado incidente por la Ley Orgánica del Tribunal Constitucional 6/2007, de 24 de mayo , éste se incardina en el sistema de garantías de los derechos fundamentales ( STC 43/2010, de 26 de julio ), con la finalidad de agotar la vía jurisdiccional previa al recurso de amparo, dando ocasión al órgano judicial para reparar las vulneraciones de los derechos que se cometan en resoluciones frente a las que no quepa recurso, sin que de su inadmisión o desestimación se derive, por regla general, vulneración autónoma de los mismos ( SSTC 107/2011, de 20 de junio, FJ 1 ; y 25/2012, de 27 de febrero , FJ 5, y ATC 124/2010, de 4 de octubre , FJ 2).»

Sin embargo, pese a que la intención fue ésta, la reforma causó ciertos problemas de cara a la estrategia procesal más adecuada a la hora de proteger un derecho fundamental

Sin perjuicio de que el recurso de amparo siguiera siendo un recurso de tutela de derechos fundamentales, lo que hizo el legislador fue configurar un sistema de garantías de los derechos fundamentales encomendando a los Jueces y Tribunales de la jurisdicción ordinaria el papel de naturales y primeros garantes de dichos derechos, a los que confirió un mayor protagonismo en su protección con la ampliación de esta figura. Pero no sólo esto, con la nueva regulación del incidente, además de subrayar esta posición de la jurisdicción ordinaria como garante principal, se permite a los Jueces y Tribunales la posibilidad de rectificar su posición en aquellos supuestos en los que presuntamente han vulnerado un derecho fundamental.

Por tanto, podemos apreciar una doble mejora (en principio) para la jurisdicción ordinaria: el fortalecimiento de la posición de los Jueces y Tribunales de la jurisdicción ordinaria como principales garantes de los derechos y la posibilidad de rectificación en caso de error sin necesidad de acudir al amparo constitucional. De este modo, con la nueva regulación, se remarcó el carácter extraordinario y subsidiario del recurso de amparo constitucional, otorgando así al TC el papel de garante último y máximo intérprete de la CE. En este sentido parece manifestarse RUÍZ RUÍZ ${ }^{9}$ cuando afirma que la reforma de 2007 comporta un importante incremento de las facultades de la jurisdicción ordinaria en la tutela de los derechos fundamentales y que, asimismo, la nueva regulación del incidente potencia esta jurisdicción en su función de primer y natural garante de los derechos de los individuos.

Sin embargo, consideramos cuestionable esta pretensión de remarcar el carácter de los jueces y tribunales de la jurisdicción ordinaria como principales garantes de los derechos fundamentales mediante la reforma del IENA. A pesar de ser ésta la intención del legislador con la reforma, la práctica ha sido muy distinta, pues esta figura no ha realizado tal labor y, a nuestro parecer, crea más problemas que soluciones. Y es que, con esta configuración, el incidente sólo puede ser interpuesto cuando la parte no haya dispuesto de otro instrumento para presentar sus alegaciones previamente a la sentencia o resolución que ponga fin al proceso. Es por ello que sólo cobrará sentido ante vulneraciones del derecho a la tutela judicial efectiva o de las garantías procesales derivadas del artículo $24 \mathrm{CE}$ acaecidas después de recaer sentencia firme o producidos

«especial trascendencia constitucional» que impuso el art. 50.1 b) de la LO 2/1979, de 3 de octubre, para la admisión del recurso de amparo. Con tal nuevo requisito, ya no sería suficiente la mera lesión de un derecho fundamental o libertad pública para articular el recurso de amparo.

${ }^{9}$ RUÍZ RUíZ, J. J., Op. Cit., pág. 319. 
por la propia sentencia firme. ${ }^{10}$ Además, si tenemos en cuenta que quien resolverá el incidente será el mismo juzgado o tribunal que dictó la resolución que supuestamente vulneró el derecho fundamental, vemos que van a ser muy pocos los casos en los que esta figura cobre sentido como garantía de protección de los derechos fundamentales. Por tanto, pese a ser buena la intención de su reforma, la realidad es que, en lugar de encontrarnos ante un plus de garantía en la jurisdicción ordinaria que otorgue una posibilidad más de protección de los derechos fundamentales, lo que encontramos es un óbice procesal más, necesario antes de acudir al amparo y que entorpece el camino en lugar de hacerlo más corto.

\section{El carácter no devolutivo}

El IENA debe presentarse, atendiendo a su regulación, ante el mismo órgano judicial que haya producido la actuación cuya nulidad se pretende.

Consideramos que esta es una de las características más importantes que hacen de esta figura, en nuestra opinión, una herramienta insuficiente para la protección de los derechos fundamentales, más aún si tenemos en cuenta que en la reforma de 2007 se amplió su objeto con la intención de "compensar" la objetivación del recurso de amparo y ofrecer así una supuesta mejor protección de los derechos fundamentales en la vía ordinaria.

El principal problema que observamos, derivado de la propia configuración de la figura, es que el incidente sólo resulta efectivo cuando la posible nulidad se deba a errores de hecho producidos en la tramitación de los procesos, que obedezcan al incumplimiento de trámites de carácter formal y que resulten fácilmente detectables, de manera que no ofrezcan duda. Y es que resulta realmente complicado que el órgano judicial que haya resuelto el asunto de fondo mediante una sentencia o resolución de inadmisión, o que haya decidido sobre cualquier trámite que requiera alguna consideración de naturaleza jurídica, reconsidere la decisión que consideró correcta en su momento y acceda a declarar nula dicha decisión poco tiempo después.

Consideramos, por tanto, que habría sido más adecuada que esta tarea la hubiera desempeñado el superior jerárquico, ya que, en base a lo anterior, es más probable que un órgano distinto al que resolvió la pretensión reconsidere la decisión que consideró correcta el órgano inferior y la declare nula. Vemos pues que este hecho dificulta una adecuada tutela judicial efectiva en lugar de facilitarla, que es lo que perseguía la reforma.

\section{Derechos invocables}

El tercer problema que observamos en torno a esta figura es el de la ampliación de los derechos invocables. La redacción dada al art. 241 LOPJ tras la reforma amplió el objeto del incidente a la invocación de cualquier derecho fundamental de los referidos en el art. 53.2 CE. Sin embargo, la dinámica de su funcionamiento y la imposibilidad de invocar por esta vía la vulneración de derechos que hubieran podido

${ }^{10}$ En este punto es interesante consultar: CARRASCO DURÁN, M., "La definición constitucional del derecho a la tutela judicial efectiva”, Revista de Derecho Político, núm. 107, 2020, págs. 13-40. 
denunciarse antes de recaer resolución que ponga fin al proceso, hacen que, en la práctica, el artículo que se invoque en la inmensa mayoría de los casos sea el $24 \mathrm{CE}^{11}$.

Existirán generalmente dos opciones ante una resolución que, presuntamente, vulnere un derecho fundamental: la primera sería que, frente a esa resolución no existiese la posibilidad de presentar un ulterior recurso, caso poco común. La única posibilidad que se plantea sería la de interponer el IENA. Utilizada esta vía, se considerará agotada la vía judicial ordinaria, sólo quedaría, por tanto, la posibilidad de acudir al recurso de amparo. Será en estos casos en los que se aprecien incidentes que aleguen cualquiera de los derechos fundamentales recogidos en el Capítulo Segundo, Sección Primera de nuestra Constitución. Esto es debido a que, al encontrarnos en asuntos de única instancia, cabe la posibilidad de que el juez, al resolver, vulnere cualquiera de los derechos fundamentales. Sería únicamente en estos casos donde podría apreciarse un mínimo atisbo de la utilidad práctica de esta ampliación del objeto del IENA.

La segunda opción sería que sí cupiesen ulteriores recursos antes de presentar el incidente, como suele ocurrir en la mayoría de los casos. Debemos tener presente que no cabe la posibilidad de traslación, es decir, no podemos presentar en segunda instancia un IENA por una vulneración de un derecho que se produjo en la primera. Por tanto, para poder presentar el incidente es necesario que sea ese superior jerárquico el que vulnere en su resolución un derecho fundamental, por ejemplo, no motivando la sentencia en relación al derecho vulnerado y haciéndolo sobre otro tema. Serán estos incidentes, los mayoritarios, los que aleguen el art. $24 \mathrm{CE}$, ya que, será difícil que el juez de segunda instancia vulnere otro derecho distinto al 24 al resolver el recurso presentado.

Vemos pues dos causas por las que no consideramos acertada esta ampliación del objeto del IENA. La primera, relativa al hecho en sí mismo de ampliar el objeto teniendo en cuenta que son mínimas las ocasiones en las que el incidente se va a presentar alegando un derecho distinto del 24 CE. La segunda, la configuración en sí de esta figura que hace imposible invocar por esta vía la vulneración de derechos que hubieran podido denunciarse antes de recaer resolución que ponga fin al proceso, hecho que reitera esa “monopolización” de la invocación del art. 24 CE.

Por todo esto, consideramos del todo inadecuada la regulación dada a esta figura si lo que se persigue es una mayor garantía de los derechos fundamentales en la jurisdicción ordinaria y reafirmar la posición de los jueces y tribunales de dicha jurisdicción como principales garantes de los derechos fundamentales. A nuestro parecer, no se ha producido una ampliación de la tutela efectiva de los derechos fundamentales pues la ampliación del catalogo de derechos que pueden ser objeto del IENA es ficticia ya que, salvo en los casos de un proceso de única instancia, no habrá posibilidad de alegar otro derecho que no sea el $24 \mathrm{CE}$. Tampoco se ha ampliado el derecho a la tutela judicial efectiva como derecho en sí mismo debido a que, por una parte, se ha aumentado la incertidumbre del justiciable acerca de la pertinencia o no de interponer el incidente. Por otra parte, el hecho de que sea resuelto por el mismo juez que dictó la resolución no nos parece acertada ya que son muy escasas las ocasiones en las que éste reconocerá su error. Por último, creemos que el proceso llega a hacerse más

\footnotetext{
${ }^{11}$ En este sentido, GÓMEZ FERNÁNDEZ, I. y MONTESINOS PADILLA, C., "Una década de incidente de nulidad de actuaciones: ¿aclaración, reforma o supresión?”, Revista de Derecho Constitucional, núm. 113, 2018, pág. 80.
} 
lento e incierto, pareciendo esta figura más un recurso dilatorio que un remedio judicial efectivo.

\section{LA RELACIÓN ENTRE EL INCIDENTE “EXCEPCIONAL” DE NULIDAD DE ACTUACIONES Y EL RECURSO DE AMPARO CONSTITUCIONAL}

\section{El incidente "excepcional" de nulidad de actuaciones como medio de acceso al recurso de amparo}

La subsidiariedad del recurso de amparo viene establecida por la LOTC y la propia $\mathrm{CE}^{12}$. Por ello, es necesario el agotamiento de «la vía judicial procedente», cuando se recurre en amparo frente a actos de la Administración o del Gobierno (art. 43 LOTC) o, en su caso, que «se hayan agotado todos los medios de impugnación previstos por las normas procesales para el caso concreto dentro de la vía judicial» cuando el recurso de amparo pretenda interponerse frente a violaciones de los derechos y libertades susceptibles de amparo constitucional, que tuvieran su origen inmediato y directo en un acto u omisión de un órgano judicial (art. 44.1 a). ${ }^{13}$

En el segundo supuesto, recurso de amparo frente a resoluciones judiciales, la jurisprudencia constitucional ha interpretado de forma rigurosa la exigencia del agotamiento de la vía judicial previa. Se han incluido dentro de los medios de

\footnotetext{
12 Puede consultarse en este punto: ARAGÓN REYES, M., "El incidente de nulidad de actuaciones como remedio previo al recurso de amparo. La función del Ministerio Fiscal”, Teoría y Realidad Constitucional, núm. 28, 2011. BARBER BURUSCO, S., "La reciente doctrina del Tribunal Constitucional sobre el incidente de nulidad de actuaciones”, Actualidad Jurídica Aranzadi, núm.880 Parte Tribuna, 2014. CHOZAS ALONSO, J. M., "La expansión del incidente de nulidad de actuaciones por motivos procesales. A propósito de la STC 43/2010, de 26 de julio”, Derecho Privado y Constitución, núm. 25, 2011. FONTESTAD PORTALÉS, L., "El incidente de nulidad de actuaciones: un sistema de amparo "ordinario" frente al amparo constitucional”, en:
} https://riuma.uma.es/xmlui/handle/10630/10232.

13 Para una mayor profundización sobre este punto puede consultarse: BELADÍEZ ROJO, M., "La función constitucional del incidente de nulidad de actuaciones del art. 241 LOPJ”, en L. ARROYO JIMÉNEZ; M. BELADIEZ ROJO; C. ORTEGA CARBALLO y J. M. RODRÍGUEZ DE SANTIAGO, El juez del derecho administrativo. Libro homenaje a Javier Delgado Barrio, Madrid, 2015. CARRASCO DURÁN, M., "El incidente de nulidad de actuaciones: problemas y algunas soluciones”, Revista Aranzadi Doctrinal, núm.3, 2013; CARRASCO DURÁN, M., "La tutela de los derechos fundamentales a través del incidente de nulidad de actuaciones”, Revista Española de Derecho Constitucional, núm. 95, mayoagosto 2012, págs. 65-93. CARRETERO SÁNCHEZ, S., “Acerca de la nulidad de actuaciones y su complicada clarificación constitucional”, Diario La Ley, 8291, 2014. GARCÍA-VILLARUBIA BERNABÉ, M., “A vueltas con el incidente de nulidad de actuaciones y el recurso de amparo. Examen de la cuestión a la vista de los recientes avances legislativos y jurisprudencial”, Diario La Ley, núm. 6156, 2004. GORRIZ GOMEZ, B., "Modificación de la doctrina constitucional sobre la necesidad de interponer el incidente de nulidad de actuaciones con carácter previo al recurso de amparo (STC 216/2013, de 19 diciembre)”, Diario La Ley, núm. 8275, Sección Tribuna, 2014. MONTESINOS PADILLA, C., La tutela multinivel de los derechos desde una perspectiva jurídico procesal, Valencia, 2017. NAVARRO MASSIP, Y., "El incidente de nulidad de actuaciones en el proceso penal y el recurso de amparo: entre la inutilidad y la intrascendencia”, Aranzadi Doctrinal, núm.5, 2009. SOSPEDRA NAVAS, F. J., "Los requisitos procesales del recurso de amparo: el incidente excepcional de nulidad de actuaciones y la especial trascendencia constitucional”, Cuadernos de Derecho Local, núm. 39, 2015. TRIANA REYES, B., “¿Qué hacer antes de acudir al amparo?: el Tribunal Supremo contesta”, Diario La Ley, núm. 9129, Sección Tribuna, 2018. VILLALVILLA MUÑOZ, J. M., "El intrincado laberinto del incidente de nulidad y el recurso de amparo”, Anuario contencioso para abogados 2011: los casos más relevantes sobre litigación y arbitraje en 2010 de los grandes despachos, Madrid, 2011. 
impugnación necesarios algunos que, no siendo recursos en sentido estricto, han sido considerados adecuados para la reparación de la lesión del derecho fundamental, tal es el caso de la revisión de sentencias o, en lo que ahora interesa, el IENA.

Aunque en el siguiente punto haremos un mayor hincapié en la doctrina constitucional relacionada con este tema, es importante mencionar en este punto la STC 107/2011, de 20 de junio, FJ 5, la cual mencionó el protagonismo otorgado por la reforma 6/2007 a los tribunales ordinarios acentuando su función como primeros garantes de los derechos fundamentales, afirmando, al igual que lo hiciera en la STC 43/2010, de 26 de julio, FJ 5, que Esta figura constituye un instrumento idóneo para la tutela de los derechos fundamentales, y que su resolución debe tener presente que, de no tener el caso trascendencia constitucional, se tratará de la última vía que permita la reparación de la vulneración denunciada. Hecho con el que, como hemos señalado, discrepamos totalmente.

La STC 153/2012, de 16 de julio, FJ 3, también reiteró la idea de que la mera lesión de un derecho fundamental o libertad pública tutelable en amparo ya no será por sí sola suficiente para admitir el recurso. En ella el Alto Tribunal que afirmó que "el incidente de nulidad de actuaciones asume, tras la configuración del nuevo amparo constitucional, una función esencial de tutela y defensa de los derechos fundamentales que puede y debe ser controlada por este Tribunal cuando las hipotéticas lesiones autónomas que en él se produzcan tengan «especial trascendencia constitucional”.

Vemos, por tanto, como la intención del TC es la de considerar que el IENA no sea un mero trámite formal previo al amparo constitucional, sino un verdadero instrumento procesal que, en la vía de la jurisdicción ordinaria, pueda remediar aquellas lesiones de derechos fundamentales que no hayan "podido denunciarse antes de recaer resolución que ponga fin al proceso y siempre que dicha resolución no sea susceptible de recurso ordinario ni extraordinario" (art. 241.1 LOPJ).

Esta consideración nos parece inadecuada, principalmente debido al carácter marcadamente "extraordinario" del incidente. Esta condición hace que este supuesto "plus” de protección de los derechos se quede en lo anecdótico pues, precisamente ese carácter marcadamente extraordinario y subsidiario de la propia figura hace que sean mínimas las ocasiones en las cabría su uso. Por tanto, si la intención fue la de compensar la objetivación del recurso de amparo, nos parece realmente insuficiente la forma en que se hizo. Por otra parte, otro problema de gran importancia que se nos plantea, es la cuestión de cómo hallar procesalmente la estrategia más adecuada de cara a la posibilidad de plantear el recurso de amparo en caso de que el incidente no sea estimado.

\section{Problemática entre el incidente "excepcional de nulidad de actuaciones y el recurso de amparo constitucional}

Los problemas entre el IENA y el recurso de amparo surgen, principalmente, cuando se dé la existencia de una controversia en la que se acumulen pretensiones que permitan presentar el recurso de amparo sin acudir previamente al incidente de nulidad de actuaciones, debido a que éstas fueron presentadas a la consideración de los órganos judiciales a lo largo del proceso previo, y pretensiones de nulidad de actuaciones que exijan presentar previamente el incidente, al haber sido originada una vulneración de derechos fundamentales en la sentencia o resolución que pusiera fin al proceso o en 
alguna actuación producida en la tramitación de aquél, sin que la parte, en tal caso, hubiese tenido ocasión de solicitar la reparación de la lesión ocasionada a su derecho ${ }^{14}$.

Se nos presentan dos soluciones no carentes de problemas. La primera sería la de inadmitir por prematuros los recursos de amparo presentados mientras esté pendiente el IENA. La segunda consistiría en que la parte interponga siempre el incidente de nulidad de actuaciones (para así agotar adecuadamente la vía judicial) y, posteriormente, y en caso de resolución desfavorable de aquél, presentar un recurso de amparo acumulando en él todos los motivos de los que se derivara alguna lesión de los derechos fundamentales tutelados por este proceso ${ }^{15}$.

Analizaremos a continuación ambas soluciones.

A. La imposibilidad de simultanear el incidente “excepcional” de nulidad de actuaciones y el recurso de amparo: los amparos prematuros.

Hablaremos a continuación de la posibilidad de simultanear el IENA y el recurso de amparo, técnica que en ocasiones intentan los recurrentes ante la problemática que presentan los plazos de ambos recursos.

La doctrina del TC al respecto es la de inadmitir los recursos de amparo interpuestos de forma simultánea al incidente, imputando como causa de inadmisión la falta de agotamiento de la vía judicial previa. Esta interpretación del TC sería muy acertada a nuestro parecer dado que el recurso de amparo es "subsidiario" y no "alternativo".

Nuestro Alto Tribunal considera para estos casos que el recurso de amparo sería inadmisible por prematuro, sin posibilidad de subsanación. Al respecto se ha posicionado en varias ocasiones:

Tan sólo un año después de la entrada en vigor de la reforma de 2007, el TC ya dispuso que se consideraría prematuro aquel recurso de amparo interpuesto paralelamente a un IENA ${ }^{16}$.

En esta misma línea, la STC 199/2012, de 12 de noviembre, siguiendo la línea de la anterior STC 99/2009, de 27 de abril, FJ 2, declaró la concurrencia del óbice procesal de la falta de agotamiento de la vía judicial previa [art. 50.1 a), en relación con el art. 44.1 a) LOTC], al haberse hecho coexistir la jurisdicción de amparo con la vía judicial ordinaria pues, en este caso, la demandante compareció ante el TC cuando aún no se habían resuelto los medios de impugnación que había puesto en marcha dentro de la vía judicial previa provocando así la coexistencia temporal de ambos procedimientos, el de la jurisdicción ordinaria y el proceso de amparo.

\footnotetext{
${ }^{14}$ CARRASCO DURÁN, M., Op. Cit., pág. 79.

${ }^{15}$ Ibidem.

${ }^{16}$ Podemos verlo en la Sentencia 73/2008, de 23 de junio, FJ 3:

«... el recurrente, callándolo en aquélla, abría una vía de impugnación paralela al promover ante la Sala sentenciadora incidente de nulidad de actuaciones del art. 241 LOPJ, por entender que la Sentencia incurría en incongruencia omisiva, incidente que fue desestimado por Auto de 5 de diciembre de 2005. Todo lo relatado evidencia que en el momento de interponer la demanda de amparo no se habían agotado los medios de impugnación que el recurrente, por decisión propia e independientemente de si son procedentes o no, había puesto en marcha dentro de la vía judicial, lo que confiere a la demanda de amparo la condición de prematura y determina, en consecuencia, que proceda su inadmisión, de conformidad con lo establecido en el art. 50.1 a) en relación con el art. 44.1 a) LOTC, y sin que, por lo tanto, sea necesario examinar ahora el fondo de los motivos en que se funda.».
} 
La STC 139/2014, de 7 de octubre, FJ 3, manifestó que consideraba opuesto al carácter subsidiario de la jurisdicción constitucional simultanear un recurso de amparo con otro recurso seguido en la vía judicial ordinaria. Un ejemplo de ello es el caso de que se inicie un proceso de amparo antes de que estén resueltos los recursos interpuestos contra la resolución judicial impugnada en vía ordinaria cuando, una vez presentada la demanda de amparo, se reabre la vía judicial durante la pendencia del proceso de amparo, aunque la resolución final de la jurisdicción ordinaria sea finalmente desestimatoria.

Queda clara, por tanto, la posición del TC a este respecto:

- El recurso de amparo es un recurso subsidiario y extraordinario, por lo que sólo debe utilizarse como última instancia una vez agotada la vía judicial previa.

- Tras la reforma de 2007, el IENA ha de ser interpuesto necesariamente para agotar la vía judicial previa.

- El IENA debe interponerse necesariamente antes de acudir al amparo y no a la vez. En el caso de interponerse a la vez, el recurso de amparo será necesariamente inadmitido por prematuro al considerarse como no agotada la vía judicial previa, requisito imprescindible para que se admita este recurso.

Sin embargo, distinto sería el caso de que se inadmitiese el originario recurso de amparo por esta circunstancia y, posteriormente, se dictase resolución en el incidente. En este caso, sería posible ahora reiterar un segundo recurso de amparo frente a esta última resolución ${ }^{17}$. Este segundo recurso de amparo, posterior al IENA, sería totalmente procedente, pues se habría agotado adecuadamente la vía judicial y en él cabría alegar vulneraciones de derechos fundamentales respecto de la resolución judicial resolutoria del incidente, así como la reproducción de todos los motivos de amparo alegados, en su caso, contra las Sentencia de apelación y casación en el recurso de amparo inadmitido por extemporáneo, incluyendo la incongruencia omisiva denunciada en el IENA.

Consideramos pues que no podrían considerarse este tipo de amparos como extemporáneos por dilaciones indebidas al alargar artificialmente la vía judicial previa. En nuestra opinión, independientemente del carácter prematuro del primer recurso de amparo ya inadmitido de manera correcta, en este segundo recurso se habría producido un correcto agotamiento de la vía judicial previa mediante la adecuada interposición de un IENA fundamentado en la incongruencia del fallo.

\footnotetext{
${ }^{17}$ En este sentido, la STC 51/2010, de 4 de octubre, FJ 2:

«En el presente caso, la entidad demandante interpuso un primer recurso de amparo contra la Sentencia de casación que fue considerado prematuro por haber simultaneado dicho recurso con la interposición del incidente de nulidad de actuaciones. Ahora bien, tras la resolución del citado incidente de nulidad de actuaciones la entidad demandante interpuso el presente recurso de amparo dentro del plazo previsto en el art. 44.2 LOTC, en él se han alegado vulneraciones de derechos fundamentales respecto de la resolución judicial resolutoria del incidente de nulidad y, además, se han reproducido todos los motivos de amparo imputados contra las Sentencia de apelación y casación en el recurso de amparo inadmitido, incluyendo la incongruencia omisiva denunciada en el incidente de nulidad.

Por tanto, tal como indica el Ministerio Fiscal, no cabe considerar que el presente recurso de amparo resulte extemporáneo en relación con las vulneraciones imputadas a las Sentencias de apelación y casación por alargamiento artificial de la vía judicial previa, toda vez que, más allá del carácter prematuro del primer recurso de amparo ya inadmitido, en este segundo recurso se ha producido un correcto agotamiento de la vía judicial previa a través de la interposición de un incidente de nulidad de actuaciones que no puede ser calificado de improcedente al haberse fundamentado en incongruencia del fallo.»
} 
En la línea apuntada por GÓMEZ FERNÁNDEZ y MONTESINOS PADILLA en relación al ATC 35/2011, "En todo caso, no cabe presentar simultáneamente la misma queja a través de un incidente de nulidad de actuaciones y de un recurso de amparo porque, llegando este dato a conocimiento del TC, el amparo será siempre inadmitido por prematuro, y no es imposible, aunque tampoco habitual, que una nueva visita al TC, una vez resuelto el incidente, acabe viéndose frustrada por la oposición de un óbice de extemporaneidad del amparo, al considerarse improcedente el incidente de nulidad". ${ }^{18}$

Vemos, por tanto, hasta qué punto es imposible la opción de simultanear el IENA y el recurso de amparo constitucional, incluyéndose casos como el anteriormente citado en el que se pretende desgajar los motivos de impugnación y denunciar, en la demanda de amparo, vulneraciones de derechos previamente invocados en el procedimiento, y en el escrito de interposición del incidente, lesiones imputables exclusivamente a la resolución que le pone fin.

Atendiendo a esto, solo procedería interponer el incidente cuando éste sea preceptivo, sin embargo, es necesario reflexionar acerca de cuándo lo será.

B. La preceptiva interposición del incidente “extraordinario” de nulidad de actuaciones previa al recurso de amparo.

Los arts. 43, 44 y 49 LOTC comprenden el conjunto de requisitos exigibles para que una demanda de amparo pueda ser admitida a trámite y para que, tras ello, sea posible que el TC entre a resolver el fondo de la pretensión deducida.

Dentro de las exigencias procesales más relevantes que contempla la norma, se encuentran las siguientes:

- La interposición extemporánea

- El correcto agotamiento de la vía judicial

- La formal y previa invocación en sede jurisdiccional ordinaria del derecho o derechos fundamentales pretendidamente vulnerados.

En base a esta última, se posibilita la reparación de la alegada quiebra constitucional por parte de la jurisdicción ordinaria sin tener que acudir directamente al TC, objetivo que perseguía la reforma de 2007.

De los citados requisitos, los dos primeros son los que mayores problemas aplicativos han suscitado, convirtiéndose ambos en una fuente inagotable de conflictos para el intérprete, por ello, nos centraremos en ellos.

\section{a) La interposición extemporánea}

Debemos precisar que el art. 44 LOTC, al exigir que se hayan agotado todos los medios de impugnación previstos por las normas procesales para el caso concreto dentro de la vía judicial, incluye tanto los recursos como el incidente de nulidad de actuaciones.

El IENA se configura como un requisito procesal de necesario agotamiento previo, basándose para esto en la subsidiariedad del amparo, más aún desde la reforma de 2007 (STC 62/2008, de 26 de mayo). No cabría duda, por tanto, acerca de la necesidad de acudir al incidente para agotar la vía judicial previa en los casos en que la

${ }^{18}$ GÓMEZ FERNÁNDEZ, I. y MONTESINOS PADILLA, C., Op., Cit., pág. 74. 
lesión del derecho se impute a la última de las resoluciones judiciales frente a la que no quepa recurso alguno (STC 89/2011, de 6 de junio).

Por otra parte, debemos tener presente que la interposición de un recurso manifiestamente improcedente suspende el plazo legalmente establecido para acudir en amparo ante el TC (SSTC 30/1982, de 1 junio; 50/1984, de 5 abril, 210/1994, de 11 julio). Por ello, la presentación no justificada de un IENA podría frustrar la posible reparación en sede constitucional del derecho fundamental lesionado, ya que su improcedente planteamiento convertiría al incidente en un recurso improcedente y, por ende, en un modo de alargamiento artificial de la vía judicial, que no impediría el inicio del cómputo del plazo para interponer el recurso de amparo, y que por tanto abocaría a la desestimación de éste por extemporaneidad.

Un ejemplo de esto son las SSTC 17/2012, de 13 de febrero y 23/2012, de 27 de febrero, en las cuales se inadmite por extemporaneidad el recurso de amparo formulado, ya que en ambos supuestos la supuesta lesión del derecho fundamental no surgió en la última de las resoluciones sino en la primera sentencia dictada en la instancia, cuyo fallo es posteriormente confirmado en apelación y más tarde en casación ${ }^{19}$.

De la incertidumbre en esta materia es consciente incluso el propio TC, como reconoce en la STC 13/2011, de 28 de febrero, cuando admite que "se sitúa al justiciable ante una delicada disyuntiva sobre el modo en que debe dar adecuada satisfacción al referido requisito procesal que franquea el acceso al amparo, puesto que una actitud medrosa o, por el contrario, arriesgada en el cálculo de la estrategia procesal pertinente puede conducir a un incumplimiento por defecto o por exceso que dé lugar a la producción del referido óbice procesal, haciendo que la demanda de amparo resulte extemporánea”.

Esta misma resolución introdujo un nuevo matiz ya que estableció que no cabrá calificar como extemporánea la demanda de amparo en caso de que venga precedida de un agotamiento no plenamente exigible en la vía judicial, si es que en ello no se aprecia "ánimo dilatorio". Este punto es sumamente importante ya que, en caso contrario, cualquier recurso interpuesto con ánimo dilatorio hará que el recurso de amparo no pueda ser admitido. Así lo estableció el TC en su STC 200/2012, FJ $3^{20}$.

\footnotetext{
19 Por tanto, las mencionadas sentencias mantienen en su argumentación que "la formulación del incidente de nulidad frente a la Sentencia de casación era manifiestamente improcedente, dado que en el incidente se denunció por la recurrente la lesión de un derecho fundamental (el garantizado por el art. 20.1 CE) que no derivaba originariamente de dicha Sentencia, sino de las Sentencias anteriores de primera instancia y apelación, pues en las dos instancias ya se había planteado la posible vulneración del citado derecho. No se trata, así, de una supuesta lesión de un derecho fundamental "que no haya podido denunciarse antes de recaer resolución que ponga fin al proceso".

20 «El art. 43.2 LOTC exige que el recurso de amparo se interponga en el plazo de los veinte días siguientes a la notificación de la resolución recaída en el previo proceso judicial. Pues bien, tal y como señalamos, entre otros, en el fundamento jurídico 1 del ATC 177/2010, de 24 de noviembre, este plazo es de caducidad, improrrogable, no susceptible de suspensión y en modo alguno puede quedar al arbitrio de las partes. Por ello no cabe su alargamiento o suspensión mediante la prolongación artificial de la vía judicial previa al recurso de amparo a través de la interposición de recursos manifiestamente improcedentes, de modo que "el tiempo invertido en la resolución de esos medios de impugnación manifiestamente improcedentes, cuando exceda del plazo establecido para presentar el recurso de amparo, determinará la extemporaneidad de éste” (por todas, SSTC 72/1991, de 8 de abril, FJ 2; 78/2000, de 27 de marzo, FJ 2; 185/2004, de 2 de noviembre, FJ 3; y 323/2006, de 20 de noviembre, FJ 2).” (ATC 42/2010, de 12 de abril, FJ 2).(...) Y en el mismo Auto que acabamos de citar (FJ 2) declarábamos "que, con arreglo a lo dispuesto en el párrafo primero del art. 241.1 LOPJ (en la redacción que le ha dado la Ley
} 
Teniendo en cuenta esta argumentación, el TC inadmitió el recurso de amparo por considerarlo extemporáneo al excederse el plazo para su interposición como consecuencia de la indebida interposición de un IENA.

En conclusión, la interposición de recursos manifiestamente improcedentes determinará la extemporaneidad del recurso de amparo debido, principalmente, al entendimiento de la interposición de estos con un ánimo dilatorio.

Por otra parte, el ATC 98/2016 exigió que el amparo se presentase en fecha posterior a la notificación de la inadmisión o desestimación del incidente, puesto que también se consideraría interposición simultánea la interposición de la demanda de amparo una vez resuelto el IENA si no ha sido notificada la resolución ${ }^{21}$. En nuestra opinión, consideramos que esta exigencia sería un "formalismo enervante" ya que se estaría dando lugar a una inadmisión del recurso de amparo, habiéndose agotado la vía previa, simplemente por el requisito formal de haber recibido la notificación de la resolución del incidente.

Entendemos la necesidad de evitar la simultaneidad de ambas figuras en aras de salvaguardar la naturaleza subsidiaria del amparo, para así evitar pronunciamientos sobre eventuales vulneraciones de derechos fundamentales cuando los órganos judiciales tienen todavía la ocasión de reestablecerlos, sin embargo, consideramos necesario evitar caer en "formalismos enervantes" que impidan la protección de derechos fundamentales.

El IENA resultará improcedente cuando sea posible presentar otro tipo de recursos ordinarios o extraordinarios, así lo exige el art. 241 LOPJ. Pero no debemos olvidar que también lo será en los casos en que se pretenda plantear nuevamente vulneraciones de derechos que ya hayan sido objeto de debate en el proceso previo y, por tanto, haya existido la posibilidad de denuncia previamente; o cuando la imputación de la lesión no pueda ser atribuida al órgano judicial ante el que se interpone el incidente ${ }^{22}$.

\section{b) El correcto agotamiento de la vía judicial}

La duda que se nos plantea sobre lo expuesto anteriormente versa sobre cuándo constituirá el IENA vía previa al recurso de amparo y cuándo no lo será.

Esta duda trae su origen en la siguiente controversia: el artículo 44.1 a) de la LOTC exige para poder recurrir en amparo "que se hayan agotado todos los medios de impugnación previstos por las normas procesales para el caso concreto dentro de la vía judicial”. Por su parte, el artículo 44.2 de la misma Ley dispone que "el plazo para

Orgánica 6/2007, de 24 de mayo), el incidente de nulidad de actuaciones no es un recurso más, sino un remedio al que se puede acudir 'excepcionalmente' para reparar la vulneración de un derecho fundamental de los referidos en el art. 53.2 CE, 'siempre que no haya podido denunciarse antes de recaer resolución que ponga fin al proceso y siempre que dicha resolución no sea susceptible de recurso ordinario ni extraordinario’.(...) En el proceso que nos ocupa, la vulneración del principio non bis in idem, recogido implícitamente en el art. 25.1 CE, ha constituido el objeto central de su reclamación en vía administrativa, de modo que la vulneración de este derecho fue denunciada antes del incidente de nulidad de actuaciones(...). De una manera similar fue articulada la demanda contencioso-administrativa, invocando en el mismo sentido la vulneración del principio non bis in idem, con cita de la STC 276/2000, de 16 de noviembre. Y en estos motivos fundamenta también el demandante de amparo, con reiteración de los argumentos esgrimidos en las sucesivas instancias, el incidente de nulidad de actuaciones.»

${ }^{21}$ GÓMEZ FERNÁNDEZ, I. y MONTESINOS PADILLA, C., Op. Cit., págs. 85-86.

${ }^{22}$ Ibídem. 
interponer el recurso de amparo será de 30 días, a partir de la notificación de la resolución recaída en el proceso judicial".

En base a ello, si no interponemos previamente el incidente, nuestro recurso de amparo podría ser inadmitido por no haber agotado toda la vía judicial previa, como impone el citado artículo 44.1 a) de la LOTC; y, a su vez, si interponemos el incidente de nulidad de actuaciones pero éste no resultaba necesario o procedente, el recurso de amparo sería extemporáneo debido a que habría transcurrido el plazo de 30 días previsto en el también citado artículo 44.2 de la LOTC, por lo que éste sería inadmitido.

La duda planteada ha sido resuelta por el TC. Sin embargo, su doctrina no ha sido del todo pacífica, sino que, por el contrario, podemos apreciar cambios en la misma a lo largo de los años. Veamos a continuación la evolución jurisprudencial que esta figura ha sufrido.

Tras la reforma de 2007, el TC mantuvo el carácter preceptivo del IENA para acudir a la vía de amparo cuando la lesión del derecho fundamental pudiese ser imputada a la resolución judicial que pusiese fin al proceso y siempre y cuando éste no pudiera ser objeto de recurso alguno, ni ordinario ni extraordinario. Por tanto, el TC exigió la presentación del incidente tanto para los casos de vulneración de derechos procesales en los que las sentencias incurriesen, por sí mismas, en una infracción vulneradora del art. $24 \mathrm{CE}$ que no hubiese podido denunciarse durante el proceso, como para los supuestos de infracción de derechos fundamentales sustantivos en los que, habiéndose debatido en el proceso sobre la vulneración de un derecho fundamental, el recurrente achaque su lesión a la sentencia dictada en última instancia. Hablamos en este último supuesto de aquellos casos en los que la lesión del derecho fundamental haya sido producida por un particular, ya que en estos supuestos la vulneración no tiene relevancia constitucional por sí misma (recordemos que el recurso de amparo es una vía abierta sólo frente a los actos de los poderes públicos), sino que la relevancia la adquiere eventualmente la resolución judicial que desestime la pretensión de tutela de este derecho.

Parecía pues que, con esta reforma, el IENA debía interponerse siempre necesariamente previo al recurso de amparo, como última vía impugnatoria prevista en la legislación procesal en los casos de vulneración de un derecho fundamental.

Hasta la reforma operada por la citada LO 6/2007, no cabía el IENA. Sin embargo, tras contemplarse esta posibilidad, el TC dispuso en el ATC 200/2010 que era preciso agotar esta vía, para atender al «propósito de potenciación o reforzamiento del recurso del amparo interponible ante este Tribunal a través de una mayor exigencia del incidente de nulidad de actuaciones». Ello respondía a la pretensión de la reforma operada en 2007.

Destacar que este Auto inadmitió el recurso de amparo interpuesto contra una sentencia de casación del Tribunal Supremo que estimaba parcialmente una demanda por intromisión en el derecho al honor, al considerar que no se había cumplido el requisito del agotamiento de la vía judicial previa debido a que no se había interpuesto el IENA.

Deducimos de este Auto que el TC pretendió establecer una mayor exigencia de esta figura revistiéndola de un carácter preceptivo en todos los casos de violaciones de derechos fundamentales, con el propósito de potenciar o reforzar el carácter subsidiario del amparo constitucional, más aún, después de la objetivación de este tras la reforma de 2007. Fue, a nuestro entender, un intento de crear una protección extra en 
la jurisdicción ordinaria para los derechos fundamentales tras el endurecimiento del acceso al TC.

En efecto, en la STC 176/2013, de 21 de octubre (citando la anterior STC 182/2011, de 21 de noviembre), el Tribunal dispuso lo siguiente:

“(...) la exigencia de agotar la vía judicial antes de acudir en amparo ante este Tribunal no reviste carácter formal, sino que sirve al fin de preservar la subsidiariedad del recurso de amparo, enfoque que necesariamente tiñe el enjuiciamiento de todo supuesto concreto. Así, el agotamiento de la vía judicial previa exige la utilización de todos los remedios procesales que reúnan la condición de pertinentes a fin de obtener ante los órganos judiciales la protección de los derechos fundamentales pretendidamente vulnerados”.

En esta línea, el TC ya había manifestado en reiteradas ocasiones, con anterioridad a la STC 176/2013, (por todas STC 11/2011, de 28 de febrero, FJ 4) que "el presupuesto procesal del agotamiento no puede configurarse como la exigencia de interponer cuantos recursos fueren imaginables, incluso aquellos de dudosa viabilidad. El agotamiento queda cumplido con la utilización de aquéllos que "razonablemente puedan ser considerados como pertinentes sin necesidad de complejos análisis jurídicos” (por todas, SSTC 85/2008, de 21 de julio, FJ 3, y 142/2009, de 15 de junio, FJ 2). No se trata, por tanto, de establecer con total precisión si un recurso es o no procedente, sino de decidir si era razonablemente exigible su interposición.

Tras la citada STC 176/2013, de 21 de octubre, el Pleno del TC dictó otra sentencia, la 216/2013, de 19 de diciembre, por la que modificó su doctrina en relación con el requisito consistente en agotar la vía judicial como paso previo a la interposición de un recurso de amparo.

Esta sentencia resuelve un recurso de amparo en relación con una sentencia de la Sala de lo Civil del Tribunal Supremo que había estimado, en casación, una demanda por intromisión en el derecho al honor y, como advirtió el Ministerio Fiscal al plantear la causa de inadmisibilidad del recurso de amparo por no haberse agotado los medios de impugnación utilizables en la vía judicial como exige el art. 241.1 LOPJ, la única resolución frente a la que se demandaba el amparo era la sentencia de la Sala Primera del Tribunal Supremo.

Sin embargo, esta causa de inadmisibilidad fue rechazada por la citada sentencia mediante un overruling ${ }^{23}$ por el Pleno del Tribunal de su doctrina anterior ${ }^{24}$. El Alto Tribunal manifestó la necesidad de revisar el requisito del agotamiento de la vía judicial previa. Se llegó a la conclusión de que, en determinados supuestos, bastaría para

\footnotetext{
23 Puede consultarse: FERNÁNDEZ SEGADO, F., "Los overruling de la jurisprudencia constitucional”, Foro, Nueva época, núm. 3, 2006, págs. 27-92.

24 «(...) debemos establecer que la conclusión a la que llegó el ATC 200/2010 al exigir en estos supuestos la interposición del incidente de nulidad de actuaciones como condición para poder considerar cumplido el requisito del agotamiento de la vía judicial previa, debe ser revisada. Este requisito del art. 44.1 a) LOTC responde, según ha sostenido de forma unánime y constante la doctrina de este Tribunal, "a la finalidad de preservar el carácter subsidiario del recurso de amparo, evitando que el acceso a esta jurisdicción constitucional se produzca per saltum, es decir, sin brindar a los órganos judiciales la oportunidad de pronunciarse y, en su caso, remediar la lesión invocada como fundamento del recurso de amparo constitucional" (por todas, últimamente, SSTC 42/2010, de 26 de julio, 91/2010, de 15 de noviembre, y 12/2011, de 28 de febrero). De modo que, en supuestos como el que ahora nos ocupa, basta comprobar que los órganos judiciales han tenido la oportunidad de pronunciarse sobre los derechos fundamentales luego invocados en vía de amparo constitucional, para estimar cumplido el mencionado requisito (...) Todo lo expuesto supone un cambio claro de criterio respecto a la doctrina desarrollada en el ATC 200/2010.»
} 
verse cumplido este requisito con comprobar que los órganos judiciales hubieran tenido la oportunidad de pronunciarse sobre los derechos fundamentales luego invocados en vía de amparo constitucional. Todo esto supuso un cambio claro de criterio respecto a la doctrina desarrollada en el ATC 200/2010.

Tras este cambio en la doctrina constitucional, para presentar ante TC un recurso de amparo contra una sentencia que ponga fin a un proceso cuyo objeto haya sido la tutela de un derecho fundamental de carácter sustantivo frente a su lesión por un sujeto particular, el recurrente podrá desde ahora (y, de hecho, deberá) interponer directamente el recurso de amparo, sin que resulte exigible el IENA.

Como hemos dicho, el recurrente tendrá la obligación de interponer directamente el recurso de amparo debido a que, cuando no sea preceptiva la interposición del incidente y aun así se lleve a cabo, su inadmisión a trámite será considerada como «un remedio procesal absolutamente improcedente» sin efectos interruptivos con relación al plazo de veinte días para la interposición el recurso de amparo (AATC 39/2010; 198/2010 y 35/2011). Por lo tanto, llegados a este extremo, el recurso de amparo sería consecuentemente inadmitido por extemporáneo. Tampoco cabría la posibilidad de utilizar a la vez ambas vías (IENA e interposición de recurso de amparo), debido a que en estos casos el TC consideraría el recurso de amparo inadmisible por ser prematuro, ya que el demandante habría comparecido cuando sin que se hubieran resuelto aún los medios de impugnación que él mismo habría iniciado en la jurisdicción ordinaria para proteger sus derechos (SSTC 199/2012 y 99/2009) ${ }^{25}$.

$\mathrm{Y}$ es que, desde este momento, el incidente de nulidad de actuaciones únicamente resultará preceptivo, en palabras de LOZANO CUTANDA y CORDÓN MORENO, "para recurrir en amparo una sentencia por vulneración de un derecho fundamental, cuando su vulneración se produzca ex novo en la sentencia (o resolución) firme que ponga fin al procedimiento, sin que haya existido debate (ni resolución) sobre la misma con anterioridad. Esto ocurrirá cuando se trate de infracciones procesales vulneradoras del art. 24 CE achacables a la propia sentencia (...), y sólo muy excepcionalmente podrá considerarse que la sentencia vulnera ex novo y por sí misma un derecho fundamental "sustantivo» no debatido en el proceso (singularmente, cuando se lesione por la sentencia el derecho de igualdad en la aplicación de la ley: SSTC 210/2002; 27/2006 y 142/2008)"26.

En conclusión, de dicha doctrina constitucional se desprende que solamente será necesario plantear previamente el IENA cuando los órganos judiciales no hayan tenido ninguna oportunidad previa de examinar la vulneración que constituye el motivo de nulidad de actuaciones. En otro caso, es decir, si ya existió oportunidad de pronunciamiento al respecto, habrá de interponerse directamente recurso de amparo.

Tras esta revisión doctrinal por parte del TC, se desvirtuó el propósito de la reforma legislativa realizada por la LO 6/2007 ya que la modificación del art. 241.1 LOPJ con la que se amplió la posibilidad de interponer el incidente previo al amparo ante la infracción de cualquier derecho fundamental, tenía como objeto el reforzamiento del carácter subsidiario del amparo con el fin, como decía su Exposición de Motivos, de «otorgar a los Tribunales ordinarios el papel de primeros garantes de los derechos fundamentales en nuestro ordenamiento jurídico».

${ }^{25}$ LOZANO CUTANDA B., CORDÓN MORENO, F., "Overruling de la jurisprudencia constitucional sobre el requisito de interponer el incidente de nulidad de actuaciones con carácter previo al recurso de amparo (STC 216/2013)", Diario La Ley, 28 de enero de 2014.

${ }^{26}$ Ibídem. 
Llama la atención que, según se apunta en la propia sentencia, esta exigencia de agotamiento de la vía judicial previa responde a la "finalidad de preservar el carácter subsidiario del recurso de amparo", de tal forma que, antes de denunciar ante el TC la vulneración de un derecho fundamental, los tribunales ordinarios deben haberse pronunciado al respecto como garantes principales de estos derechos.

En esta sentencia, sin embargo, el Tribunal limitó los casos en los que, para demandar el amparo del TC, resulta necesario plantear un incidente de nulidad de actuaciones contra la última sentencia recaída en el procedimiento.

Teniendo esto en cuenta, la Sentencia dispone que el requisito podrá considerarse cumplido, sin necesidad de interponer el incidente de nulidad de actuaciones, cuando se compruebe que los órganos judiciales han tenido la oportunidad de pronunciarse sobre los derechos fundamentales luego invocados en vía de amparo constitucional. Este hecho tiene su explicación en el propio carácter excepcional del IENA pues, pese a haberse ampliado su objeto en la reforma de 2007, este sigue siendo del todo excepcional. Por tanto, en todos aquellos casos en los que los órganos judiciales tuvieron oportunidad de pronunciarse sobre la supuesta vulneración del derecho, no cabrá su interposición.

Esto conllevaría que, cuando la vulneración de un derecho fundamental objeto de la demanda de amparo haya sido debatida en todas las instancias, debería considerarse cumplido el requisito del agotamiento de la vía judicial previa. Por tanto, partiendo de esta premisa, el incidente sería exigible sólo en aquellos casos en los que la vulneración del derecho fundamental se haya producido ex novo en la última sentencia recaída en el procedimiento.

Parece, por tanto, bastante incongruente este cambio en la doctrina del TC si tenemos en cuenta el objetivo que perseguía la reforma de 2007, que no era otro que remarcar ese carácter subsidiario del recurso de amparo potenciando la figura del juez ordinario como garante principal de la protección de los derechos fundamentales. Este hecho nos parece una muestra de la insuficiente eficacia que tiene el IENA en la práctica pues, como vemos, sólo tendrá cabida en puntuales ocasiones. Pensamos pues que, si lo que se pretendió con la reforma era potenciar el protagonismo del juez ordinario en la protección de los derechos fundamentales remarcando así el carácter subsidiario de la jurisdicción constitucional, la ampliación del objeto del incidente fue un mecanismo insuficiente para el cumplimiento de esta labor. Precisamente por estar hablando de un incidente y no de un recurso, ya que no es lo más adecuado ampliar el objeto de una figura que de por sí es extraordinaria si lo que se busca es potenciar la actuación de una jurisdicción en una labor tan importante como lo es la protección de los derechos fundamentales, máxime teniendo en cuenta que se hizo para compensar la fuerte restricción al acceso de la jurisdicción constitucional tras la reforma de 2007.

\section{El incidente "excepcional” de nulidad de actuaciones. ¿Un efectivo filtro para el acceso al recurso de amparo constitucional?}

Las estadísticas muestran que el IENA no operó eficazmente como filtro para el acceso al recurso de amparo en los primeros años.

Si observamos el número de recursos de amparo ingresados ${ }^{27}$ en el TC los primeros años tras la entrada en vigor de la LO 6/2007, vemos como ascendió de los

${ }^{27}$ Datos extraídos de las Memorias del Tribunal constitucional: 
9.840 del año 2007 a los 10.279 del año 2008 y a los 10.792 del año 2009. Posteriormente, el número de recursos de amparo descendió en 2010 hasta los 8.948; en 2011, quedó en 7.098 y, en 2012 en 7205.

Coincidimos con CARRASCO DURÁN en la idea de que no creemos que el incidente fuese la causa de tal descenso, sino, más bien, la generalización de la conciencia acerca de la dificultad de lograr la admisión del recurso de amparo, más aún tras la LO 6/2007 28 .

Sin embargo, vemos como en el siguiente quinquenio el número de recurso de amparo ingresados en el TC siguió descendiendo, desde los 7.376 de 2013, hasta los 7.663 de 2014 y los 7.203 de 2015; llegando incluso a 6.685 en 2016 y 6.286 en 2017.

Cabe, por tanto, plantearse si este descenso es debido a la labor del IENA o si se debe a un descenso en la litigiosidad por otros motivos.

Curiosamente vemos que, en los dos últimos años, 2018 y 2019, las cifras han vuelto a aumentar a 6918 y 7554 respectivamente.

No creemos pues que el descenso de recursos de amparo ingresados en estos años sea fruto de la labor del incidente, y ello por varios motivos.

Por una parte, analizadas las posibles fricciones y complicaciones a la hora de interponer esta figura y el recurso de amparo, podemos deducir que se plantean multitud de dificultades para los operadores jurídicos a la hora de lograr una efectiva estrategia procesal para la protección de sus intereses, hecho que nos resulta preocupante, especialmente si tenemos en cuenta que nos estamos refiriendo a la protección de derechos fundamentales.

Consideramos que pueden darse principalmente dos problemas básicos a la hora del estudio de una adecuada estrategia procesal: el primero sería la "traslación", es decir, incurrir en el error de pretender trasladar a la segunda instancia la vulneración de un derecho fundamental producido en la primera. Y es que, el primer punto a tener en cuenta es que se denunciar (por el medio que proceda) la nulidad de actuaciones justo en el momento es que se tenga conocimiento de ella. Por tanto, si se denuncia en una segunda instancia, será porque ha sido justamente este Tribunal el que ha vulnerado el derecho y nunca con la pretensión de trasladar a éste la vulneración acaecida en la primera instancia.

El segundo problema versa sobre la doble vertiente del artículo 24 CE debido a la confusión acerca de las posibles infracciones que pueden darse con base a este precepto. Existen, por una parte, las infracciones del art. $24 \mathrm{CE}$ de un carácter eminentemente procesal, como podría ser la falta de igualdad de las partes en el proceso, dilaciones indebidas, etc. Esta infracción se dará mayoritariamente en la sustanciación del proceso y no con la resolución propiamente dicha. Sin embargo, encontramos en un segundo lugar otra posible vertiente de este precepto, que es la que induce a confusión, donde se mezclan los temas procesales con los derechos fundamentales alegados en sí mismos.

Ante una resolución judicial en la que se considere vulnerado un derecho fundamental, aparece la duda de si se debe o no plantear un IENA. La pregunta que permitirá saber si se debe o no formular este incidente es la siguiente: ¿se ha podido denunciar la lesión del derecho fundamental "antes de recaer resolución que ponga fin al proceso" (art.241.1 LOPJ)?

https://www.tribunalconstitucional.es/es/memorias/Paginas/Cuadros-estadisticos.aspx

${ }^{28}$ CARRASCO DURÁN, M., Op. Cit., págs. 84 y ss. 
Podrían darse dos opciones al respecto:

La primera sería que, frente a esa resolución no existiese la posibilidad de presentar un ulterior recurso (recordemos que, atendiendo al art. 240 LOPJ la nulidad de las actuaciones siempre habrá de hacerse valer, en primer lugar, por medio de los recursos que establezcan las leyes procesales). Por ejemplo, una resolución de la Sala de lo contencioso-administrativo de un Tribunal Superior de Justicia. Será en estos casos cuando la única posibilidad que se plantea sea la de interponer el IENA del art. 241 LOPJ. Utilizada esta vía, se considerará agotada la vía judicial ordinaria, sólo quedaría, por tanto, la posibilidad de acudir al recurso de amparo. Será en estos casos en los que se aprecien incidentes alegados en virtud de cualquiera de los derechos fundamentales recogidos en el Capítulo Segundo, Sección Primera de nuestra Constitución y, consecuentemente, amparos basados en estos derechos.

La segunda opción sería el caso en el que frente a esa resolución judicial sí que cupiese un ulterior recurso, es decir, acudir al superior jerárquico, en apelación generalmente. Aquí podría darse una doble opción.

1. Recordemos que no cabe la posibilidad de traslación. Si ese superior jerárquico, en su resolución, no observase la tutela judicial efectiva, por ejemplo, no apreciase la existencia de vulneración del derecho fundamental alegado, sin motivación alguna, contra esta resolución se presentaría el IENA. Será en estos casos cuando básicamente, se alegue el art. 24 CE (en su segunda vertiente) ya que, será difícil que el juez de segunda instancia vulnere otro derecho distinto al 24 al resolver el recurso presentado. Si en este caso, después del incidente, se acudiese al amparo, sería obviamente alegando el art. $24 \mathrm{CE}$, debido a que esa segunda instancia habría vulnerado este derecho al resolver la apelación, como hemos dicho en el anterior ejemplo, no motivando adecuadamente la resolución. Por esta vía llegarán mayoritariamente los amparos fundamentados en el art. 24 CE que, como veremos, son muchos.

2. La segunda opción sería que, frente a esta segunda resolución, no cupiese el IENA, básicamente porque se estime la apelación, pero esta segunda instancia no haya vulnerado ningún derecho fundamental al hacerlo y, por tanto, no exista motivo para el mismo. Por tanto, después de esta segunda resolución judicial, sólo quedará la opción de acudir directamente al amparo. Al no haberse vulnerado en esta segunda instancia ningún derecho fundamental al resolver (art. $24 \mathrm{CE}$ ), en este caso, llegarán los amparos que no aleguen el art. $24 \mathrm{CE}$.

Por tanto, si la parte hubiese postulado la defensa del concreto derecho fundamental en la demanda o contestación, o si la sentencia se hubiese pronunciado sobre el particular, tendríamos ya abiertas las puertas del recurso de amparo, sin necesidad de plantear el IENA.

Por el contrario, necesariamente habría de plantearse el incidente en el caso, por ejemplo, de una incongruencia omisiva de la sentencia, tal y como señala la STC 51/2010, de 4 de octubre del 2010, FJ 2:

«De ese modo, en los supuestos en que se alegue la existencia de un vicio de incongruencia omisiva que no pueda ser reparado en la vía ordinaria resulta necesario acudir al incidente de nulidad de actuaciones con carácter previo a la interposición del recurso de amparo, para, en respeto de la subsidiariedad de esta jurisdicción, agotar correctamente la vía judicial (por todas, STC 8/2004, de 9 de febrero, FJ 2).». 
Cabe, por tanto, plantearse lo siguiente: los amparos que llegan sin haberse planteado UN IENA previo, suelen alegar la vulneración de otros derechos fundamentales distintos a los del art. $24 \mathrm{CE}$; y, por su parte, los amparos fundamentados en la vulneración del art. 24 CE, generalmente han presentado incidente previo (debido, como hemos planteado, a que generalmente la vulneración del art. 24 CE se da por el Tribunal de segunda instancia al resolver).

Partiendo de esta premisa, si consultamos las cifras y estadísticas jurisdiccionales de nuestro TC, podemos ver como el art. 24 CE sigue siendo con diferencia el más invocado, oscilando su porcentaje de invocación hasta 2011 en torno a un $85 \%$.

Sin embargo, bien es cierto que desde 2011 hasta la actualidad este porcentaje ha ido bajando paulatinamente, colocándose en la actualidad en torno a un 75\%.

Vemos pues, que casi todos los recursos de amparo siguen alegando este artículo. Por tanto, en la inmensa mayoría de los casos se da la existencia de un IENA previo.

Debido a esto, creemos que, si siguen llegando tantos amparos basados en la invocación del art. $24 \mathrm{CE}$, se debe a una insuficiente labor de la jurisdicción ordinaria previa, especialmente en la resolución de incidentes del art. 241 LOPJ. Ello debido a que, como ya hemos mencionado, la mayoría de amparos que alegan este artículo lo hacen por una vulneración producida en una segunda instancia, por lo que presentan previamente al amparo un IENA. Al no ver favorecida su pretensión en la resolución del incidente, deben recurrir al amparo.

Consideramos que una labor adecuada de esta figura produciría una considerable disminución de demandas de amparo que aleguen este artículo. Bien es cierto que, en los últimos años, hemos apreciado una disminución en el porcentaje de alegación de este artículo. No obstante, su porcentaje de invocación sigue siendo considerablemente alto, por lo que opinamos que el funcionamiento del IENA debe mejorar.

\section{El incidente “excepcional” de nulidad de actuaciones y la especial trascendencia constitucional}

El TC sostiene a día de hoy que las decisiones resolutorias del IENA son capaces de vulnerar derechos de manera autónoma, postura que anteriormente no mantenía (AATC 24/2010, 19/2011 y SSTC 107/2011 y 25/2012). Este cambio en su doctrina tuvo lugar en la STC 153/2012.

Es curioso este cambio en la doctrina constitucional pues este hecho supone abrir la puerta del recurso de amparo a este tipo de demandas. Tendría sentido, por una parte, si consideramos que contra la resolución resolutoria del incidente no cabe recurso alguno. Sin embargo, si la prioridad es (como afirmaba la LO 6/2007) la de aligerar la carga de trabajo del TC, poco sentido tiene abrir la puerta del amparo a las resoluciones del IENA considerando que sean capaces de vulnerar derechos fundamentales. Nuevamente, a nuestro parecer, el incidente de nulidad crea más problemas que soluciones.

Este tipo de vulneraciones tendrían lugar en los casos en los que el juez o el tribunal no haya reparado la lesión que fue denunciada en el incidente. Esta inadmisión o desestimación podría ser, atendiendo al TC, un “objeto complementario” del recurso de amparo que se interpondría con posterioridad atribuyéndosele a la providencia o auto 
que resolvieron la lesión denunciada en el incidente. Estos autos o providencias podrían ser considerados "objeto mixto" del amparo al imputarles la lesión del derecho objeto del incidente y, generalmente, una lesión autónoma de alguna vertiente del art. 24.1 CE o del art. 14 CE. Por último, la resolución judicial resolutoria del incidente podría ser "objeto exclusivo" de la demanda de amparo cuando se le atribuya una lesión autónoma de un derecho fundamental, y por tanto desvinculada de la lesión denunciada al plantear el incidente ${ }^{29}$.

Este hecho supone asumir que las cuestiones que se plantean en estos supuestos tienen especial trascendencia constitucional pese a referirse, como apuntan GÓMEZ FERNÁNDEZ Y MONTESINOS PADILLA ${ }^{30}$, "a la lesión de derechos que se definen por una jurisprudencia amplia, consolidada y poco controvertida. Por tanto, es la aplicación de esos derechos al ámbito específico del incidente lo que dota de especial trascendencia a los amparos, así como la voluntad evidente del TC de aclarar tanto el alcance y posición que ocupa el incidente de nulidad en nuestro sistema de garantía de los derechos fundamentales como el lugar que en el mismo corresponde a los órganos jurisdiccionales".

Estas demandas de amparo alegarían mayoritariamente una vulneración del art. 24 CE pues, al igual que sucedía anteriormente con el propio IENA, es el derecho más propio a ser vulnerado con la resolución de un órgano judicial (sirva como ejemplo el derecho de acceso a los recursos, el derecho a obtener una resolución jurídicamente fundada y no incursa en incongruencia, irrazonabilidad o arbitrariedad, etc.). Resulta curioso el hecho de que, siendo el art. $24 \mathrm{CE}$ el principal responsable de la carga de trabajo del TC y habiéndose ampliado el objeto del IENA precisamente para ofrecer una más efectiva tutela judicial efectiva en la jurisdicción ordinaria, finalmente puedan llegar al TC un significativo número de demandas de amparo que aleguen una vez más el art. 24 CE por una resolución desestimatoria de un incidente. Lo cual denota, una vez más, la ineptitud de esta figura.

Otro problema, no menos destacable, es el alcance de las sentencias de amparo cuyo único objeto es la resolución del IENA. Y es que la posible estimación del recurso únicamente supondría la retroacción de las actuaciones al momento inmediatamente anterior al dictado de la providencia o del auto que inadmitió o que desestimó el incidente. Por tanto, aunque el órgano judicial dictase una nueva resolución judicial resolviéndose en forma legal dicho incidente, esto no supondría la protección del derecho que originariamente se alegó como vulnerado en el incidente. Por ejemplo, si una sentencia de amparo declara la lesión del art. 24.1 CE por una falta de motivación en la resolución del IENA y devuelve el procedimiento a esa fase procesal, pero ese órgano judicial de instancia había vulnerado también un derecho fundamental sustantivo del justiciable (motivo por el cual se planteó inicialmente el incidente), la devolución del procedimiento le da la opción de reparar la lesión, pero no le impone la obligación de hacerlo. Así pues, el órgano judicial podría, siguiendo el ejemplo expuesto, limitarse a motivar adecuadamente la inadmisión o la desestimación del incidente, pero no tendría obligación de reparar la lesión sustantiva del derecho por el cual se interpuso el IENA. Por tanto, quedaría de nuevo abierta la posibilidad de volver a interponer un amparo, aunque, a nuestro parecer, no se estaría cumpliendo una adecuada labor de

\footnotetext{
${ }^{29}$ En este sentido, GÓMEZ FERNÁNDEZ, I. Y MONTESINOS PADILLA, C., Op .Cit, págs.94-95.

${ }^{30}$ Ibídem.
} 
tutela judicial efectiva ni de agilidad procesal, sino que, por el contrario, estaríamos sometiendo al justiciable a una compleja y lenta vorágine procesal.

\section{CONCLUSIONES}

PRIMERA: la finalidad principal de la LO 6/2007 fue la de reforzar el papel de los jueces de la jurisdicción ordinaria como garantes principales de los derechos fundamentales subrayando, a su vez, el carácter extraordinario y subsidiario de la jurisdicción constitucional en esta labor. El IENA asume, pues, tras la configuración del nuevo amparo constitucional, una función esencial de tutela y defensa de los derechos fundamentales que puede y debe ser controlada por este Tribunal cuando las hipotéticas lesiones autónomas que en él se produzcan tengan "especial trascendencia constitucional”. Así lo ha recalcado el propio TC en su posterior jurisprudencia.

SEGUNDA: uno de los principales problemas que podemos encontrar al respecto, es el hecho de que el legislador haya dispuesto para esta labor una figura de carácter igualmente excepcional como es el IENA. Consecuentemente, estamos intentado dar un plus de protección a los derechos fundamentales mediante un recurso excepcional antes de recurrir, en su caso, al TC usando otro recurso excepcional como es el amparo constitucional.

TERCERA: teniendo en cuenta que sólo el 1\% de los recursos de amparo son admitidos a trámite, podemos ver que el incidente será, en la mayoría de los casos, la última vía para la protección de los derechos fundamentales. Carece por tanto de sentido, que esta última vía de protección se lleve a cabo mediante un recurso de naturaleza extraordinaria y que, como la propia LOPJ recoge, no será admitido como regla general.

CUARTA: si consideramos que la ampliación del objeto del IENA en la reforma de 2007 tenía como finalidad que esta figura fuese considerada una nueva garantía de los derechos en la vía jurisdiccional ordinaria (una garantía alternativa al amparo, teniendo en cuenta la dificultad de acudir a este tras la introducción del requisito de la especial trascendencia constitucional), consideramos que su diseño procesal no responde a este objetivo. Ello debido, principalmente, a su carácter no devolutivo ya que, en la práctica, su estimación es bastante compleja debido al hecho en sí de que su resolución dependerá del cambio de criterio a la hora de resolver del propio órgano que originó la vulneración del derecho fundamental. En nuestra opinión, esta figura podría ser más efectiva si la resolución de la misma se llevara a cabo por un superior jerárquico ya que, de este modo, podría resolverse con una mayor objetividad.

QUINTA: resulta difícil el conocimiento de los criterios del TC a la hora de valorar cuándo será imprescindible la interposición del IENA para considerar agotada la vía judicial previa, o incluso para valorar cuándo éste será improcedente. Esta dificultad resulta incomprensible teniendo en cuenta que la adecuada interposición del incidente de nulidad será determinante para la admisión, en su caso, de un posterior recurso de amparo. Además, la doctrina constitucional no permite diseñar estrategias de litigio con garantía de éxito ya que, aún a día de hoy, los operadores jurídicos siguen teniendo dudas acerca de cuándo se debe interponer esta figura antes de acudir al recurso de amparo constitucional.

SEXTA: el recurso de amparo será considerado extemporáneo, por alargamiento de la vía judicial previa, si se interpuso un incidente «improcedente» resultando la demanda de amparo presentada fuera del plazo legalmente establecido. En 
el caso de que no se interponga el IENA y se acuda directamente al amparo, en el caso de que el TC considere que alguna de las vulneraciones denunciadas pudo denunciarse por la vía del incidente, el recurso de amparo será inadmitido por tener un carácter "prematuro".

SÉPTIMA: consideramos que el efectivo rendimiento de este instrumento se debería haber traducido en una considerable disminución de demandas de amparo que alegasen el art. $24 \mathrm{CE}$, pues esto significaría que, el juez ordinario, como garante principal de los derechos fundamentales, habría solventado las vulneraciones producidas a este derecho. Bien es cierto que, en los últimos años, hemos apreciado una disminución en el porcentaje de alegación de este artículo. No obstante, su porcentaje de invocación sigue siendo considerablemente alto, por lo que opinamos que el funcionamiento del IENA debe mejorar.

OCTAVA: creemos que no se han cumplido los objetivos que se perseguían con esta figura. Por una parte, no se ha desarrollado el IENA como una garantía adicional más del justiciable ante la jurisdicción ordinaria, nada más lejos, la realidad ha sido que esta figura se ha convertido en un óbice procesal, a nuestro parecer molesto, que entorpece y dificulta la llegada al recurso de amparo. Bien es cierto, que la intención era que no fuese necesario llegar al TC, sino que la protección la otorgase el juez ordinario, pero siendo la realidad que esta figura no otorga dicha protección y que, finalmente, es necesario acudir a éste, lo único que hace el IENA es ralentizar el camino. Por otra parte, el incidente no ayuda en absoluto en la consecución de una tutela judicial efectiva por parte de la jurisdicción ordinaria, principalmente porque, aun habiéndose ampliado su objeto, la realidad es que la mayoría de los incidentes que se presentan siguen alegando el art. 24 CE, por lo que la reforma de 2007 no ha conllevado ninguna mejora en este sentido.

NOVENA: la configuración actual del IENA hace que éste no tenga ninguna utilidad en lo que respecta a la protección de los derechos fundamentales y a la acentuación de la jurisdicción ordinaria como principal garante de los mismos. Consideramos que la mejor opción sería o bien su supresión en pro de la agilidad procesal, o bien cambiar esta configuración. Algunas opciones que creemos mejorarían dicha configuración y le darían una mayor eficacia a esta institución serían la resolución de la misma por parte de un juez distinto de esa misma instancia o por su superior jerárquico o su conversión en un recurso de carácter obligatorio para la protección de los derechos fundamentales (el TC ya reconoció en su STC 9/2014, FJ 5, que el incidente no es un recurso en sentido estricto), que podría ser resuelto por una Sala especial del TS.

DÉCIMA: entendemos que este instrumento sólo es operativo es los supuestos de error patente del juez que dictó la última sentencia que le permite reformar su propio error. Otro caso en el que podría parecer oportuno sería en los casos de procesos de única instancia ya que se permitiría ampliar la argumentación jurídica en relación al derecho fundamental.

\section{BIBLIOGRAFÍA}

AGUILERA MORALES, M., "El incidente de nulidad de actuaciones ex artículo 241 LOPJ: una mala solución para un gran problema”, Revista General de Derecho Procesal, núm. 31, 2013. 
ÁLVAREZ SÁNCHEZ DE MOVELLÁN, P., El incidente de nulidad de actuaciones. Solución o problema frente a la resolución firme, Madrid, 2015.

ARAGÓN REYES, M., "El incidente de nulidad de actuaciones como remedio previo al recurso de amparo. La función del Ministerio Fiscal”, UNED. Teoría y Realidad Constitucional, núm. 28, 2011.

BACHMAIER WINTER, L., "La reforma de la LOTC y la ampliación del incidente de nulidad de actuaciones”, Revista General de Derecho Procesal, núm., 13, octubre 2007.

BANACLOCHE PALAO, J., "La reforma del incidente de nulidad de actuaciones y el pretendido amparo judicial”, en C. Banacloche Palao, J. Banacloche PérezRoldán, B. Banacloche Palao (coords.), Justicia y Derecho tributario. Libro homenaje al profesor Julio Banacloche Pérez, Madrid, 2008.

BARBER BURUSCO, S., "La reciente doctrina del Tribunal Constitucional sobre el incidente de nulidad de actuaciones”, Actualidad Jurídica Aranzadi, núm.880 Parte Tribuna, 2014.

BELADÍEZ ROJO, M., "La función constitucional del incidente de nulidad de actuaciones del art. 241 LOPJ”, en L. Arroyo Jiménez, M. Beladiez Rojo, C. Ortega Carballo y J. M. Rodríguez de Santiago. El juez del derecho administrativo. Libro homenaje a Javier Delgado Barrio, Madrid, 2015.

BELLIDO PENADÉS, R., "El incidente de nulidad de actuaciones como medio de tutela de derechos fundamentales”, Revista General de Derecho Constitucional, núm. 25, 2017.

CARRASCO DURÁN, M., "El incidente de nulidad de actuaciones: problemas y algunas soluciones”, Revista Aranzadi Doctrinal, núm.3, 2013.

CARRASCO DURÁN, M., "La definición constitucional del derecho a la tutela judicial efectiva”, Revista de Derecho Político, núm. 107, 2020.

CARRASCO DURÁN, M., "La tutela de los derechos fundamentales a través del incidente de nulidad de actuaciones”, Revista Española de Derecho Constitucional, núm. 95, 2012.

CARRETERO SÁNCHEZ, S., “Acerca de la nulidad de actuaciones y su complicada clarificación constitucional”, Diario La Ley, núm. 8291, 2014.

CASTRO MARTÍN, J. L., MORENILLA ALLARD, P., "Sobre la inconstitucionalidad del artículo 241.1. LOPJ, en cuanto que atribuye la competencia para el conocimiento y resolución del incidente excepcional de nulidad de actuaciones al mismo Tribunal que dictó la resolución judicial firme cuya rescisión se postula”, Diario La Ley, núm. 7784, Sección Doctrina, 2012.

CHOZAS ALONSO, J. M., "La expansión del incidente de nulidad de actuaciones por motivos procesales. A propósito de la STC 43/2010, de 26 de julio”, Derecho Privado y Constitución, núm. 25, 2011.

DOIG DÍAZ, Y., “Análisis del nuevo incidente de nulidad de actuaciones en la Ley Orgánica 6/2007 de reforma del art. 241 LOPJ”, Diario La Ley, núm. 6889, Sección Doctrina, 2008.

DOIG DÍAZ, Y., "El renovado incidente de nulidad de actuaciones. A propósito de la modificación de la LOTC. Práctica de Tribunales”, Revista de Derecho Procesal Civil y Mercantil, núm.46,2008.

FERNÁNDEZ CABALLERO, G., "El incidente excepcional de nulidad de actuaciones. Teoría e incidencia práctica en el proceso civil tras su modificación por la ley 
orgánica 6/2007”, Revista Internacional de Estudios de Derecho Procesal y Arbitraje, núm. 2, 2012.

FERNÁNDEZ SEGADO, F., "Los overruling de la jurisprudencia constitucional”, Foro, Nueva época, núm. 3, 2006.

FONTESTAD PORTALÉS, L., "El incidente de nulidad de actuaciones: un sistema de amparo "ordinario" frente al amparo constitucional”. Texto íntegro disponible en: https://riuma.uma.es/xmlui/handle/10630/10232

GAMBINO, S., LOZANO MIRALLES, J., PUZZO F. y RUÍZ, J. J., El sistema constitucional español, Instituto Nacional de la Administración Pública, Madrid, 2019.

GARCÍA-VILLARUBIA BERNABÉ, M., “A vueltas con el incidente de nulidad de actuaciones y el recurso de amparo. Examen de la cuestión a la vista de los recientes avances legislativos y jurisprudencial”, Diario La Ley, núm. 6156, 2004.

GÓMEZ FERNÁNDEZ, I. Y MONTESINOS PADILLA, C., "Una década de incidente de nulidad de actuaciones: ¿aclaración, reforma o supresión?”, Revista de Derecho Constitucional, núm. 113, 2018.

GORRIZ GOMEZ, B., "Modificación de la doctrina constitucional sobre la necesidad de interponer el incidente de nulidad de actuaciones con carácter previo al recurso de amparo (STC 216/2013, de 19 diciembre)”, Diario La Ley, núm. 8275, Sección Tribuna, 2014.

LOZANO CUTANDA B., CORDÓN MORENO, F., "Overruling de la jurisprudencia constitucional sobre el requisito de interponer el incidente de nulidad de actuaciones con carácter previo al recurso de amparo (STC 216/2013)", Diario La Ley, 28 de enero de 2014.

MEGINO FERNÁNDEZ, D., El incidente de nulidad de actuaciones, Lisboa, 2010.

MONTESINOS PADILLA, C., La tutela multinivel de los derechos desde una perspectiva jurídico procesal, Valencia, 2017.

MORENILLA Allard, P., "De nuevo sobre la inconstitucionalidad del incidente de nulidad de actuaciones”, Diario La Ley. Sección Doctrina, núm. 8089, 2013.

NAVARRO MASSIP, Y., "El incidente de nulidad de actuaciones en el proceso penal y el recurso de amparo: entre la inutilidad y la intrascendencia”, Aranzadi Doctrinal, núm.5, 2009.

NOGUEIRA GUSTAVINO, M., "Contracciones y dilataciones en la reforma de la Ley Orgánica del Tribunal Constitucional: Parto prematuro del incidente de nulidad de actuaciones e incongruencia omisiva”, Teoría y Derecho, núm. 3, 2008.

RUÍZ RUÍZ, J. J., “La jurisdicción constitucional”, en AA.VV., El sistema constitucional español, Instituto Nacional de la Administración Pública, Madrid, 2019.

SOSPEDRA NAVAS, F. J., "Los requisitos procesales del recurso de amparo: el incidente excepcional de nulidad de actuaciones y la especial trascendencia constitucional”, Cuadernos de Derecho Local, núm. 39, 2015.

TRIANA REYES, B., “¿Qué hacer antes de acudir al amparo? El Tribunal Supremo contesta”, Diario La Ley, núm. 9129, Sección Tribuna, 2018.

VALDÉS DAL-RÉ, F., "El incidente de nulidad de actuaciones: su controvertida reforma por la Ley 6/2007”, Derecho de las Relaciones Laborales, núm. 2, 2015. 
A vueltas con la problemática del incidente "excepcional" de nulidad de actuaciones y su relación con el recurso de amparo constitucional

VILLALVILLA MUÑOZ, J. M., "El intrincado laberinto del incidente de nulidad y el recurso de amparo”, Anuario contencioso para abogados 2011: los casos más relevantes sobre litigación y arbitraje en 2010 de los grandes despachos, Madrid, 2011. 